\title{
Oligopolistic Competition as a Common Agency
}

Game

Cl. d'Aspremont and R. Dos Santos Ferreira

Discussion Paper 2005-18

Département des Sciences Économiques

de l'Université catholique de Louvain 


\title{
Oligopolistic Competition as a Common A gency Game
}

\author{
Claude d'A spremont* Rodolphe Dos Santos Ferreira ${ }^{\dagger}$
}

February 17, 2005

\footnotetext{
${ }^{*}$ CORE, 34 voie du Roman Pays, Université Catholique de Louvain, 1348-Louvain-laNeuve, Belgium (address for editorial correspondence).

†BETA-Theme, Université Louis Pasteur and Institut Universitaire de France.
} 


\section{A bstract}

In applying the common agency framework to the context of an oligopolistic industry, we want to go beyond the classical dichotomy between Cournot and Bertrand competition. We define two games, the oligopolistic game and the corresponding concept of oligopolistic equilibrium, and an associated auxiliary game that can be interpreted as a common agency game and that has the same set of equilibria. The parameterization of the set of (potential) equilibria in terms of competitive toughness is derived from the first order conditions of this auxiliary game. The enforceability of monopolistic competition, of price and quantity competition, and of collusion is examined in this framework. We then describe the (reduced) set of equilibria one would obtain, first in the nonintrinsic case and then in the case where a global approach would be adopted instead of partial equilibrium approach. Finally, we illustrate the use of the concept of oligopolistic equilibrium and of the corresponding parameterization by referring to the standard case of symmetric quadratic utility. 


\section{Introduction}

We propose to analyze oligopolistic competition in the common agent multiprincipal framework, as introduced by Bernheim and Whinston (1986) and further developed by Martimort, Stole and others ${ }^{1}$. This framework is known to be flexible enough for studying several economic situations such as the regulation of a firm by several government authorities, the control of a common distributor by several competing producers or, on the contrary, the relationship between several retailers distributing the output of a common manufacturer. Competition among several firms producing for a common (representative) consumer is a similarly relevant situation.

In applying the common agency framework to the context of an oligopolistic industry, we want to further pursue the objective of going beyond the classical dichotomy between Cournot and Bertrand competition. In an industry, the intensity of competition may be affected by several characteristics of each firm environment. The number of competitors, the structure of the consumer preferences, including the degree of substitutability among goods, and the cost structure are all part of the fundamentals of the industry and determine the resulting degree of competition. We are interested in still another characteristic of an industry, broadly indicated by the term "competition regime", the range of which is often reduced to the Bertrand-Cournot simple binary choice. From a modelling point of view, the determination of a competition regime may be considered as being established by selling practices and pricing policies that cannot be fully specified. Such practices and policies may include tacit agreements, explicit clauses, norms of conduct or selling mechanisms, involving firms and/or consumers, and may even require some sequencing in decisions ${ }^{2}$.

\footnotetext{
${ }^{1}$ See Stole (1991), Martimort (1992, 1996), Mezzetti (1997), Martimort and Stole (2002, 2003a, 2003b), Peters (2001), Laussel and Le Breton (2001), and references therein.

${ }^{2}$ Sequencing of decisions, such as the one analyzed by Kreps and Scheinkman (1983) to obtain the Cournot regime, is not enough per se. Some kind of rationing scheme has to be part of the construct. See Davidson and Deneckere (1986).
} 
A good example, well analyzed in the literature, ${ }^{3}$ are the so-called "facilitating practices" which include various best-price policies characterized by different clauses in the sales contract. The concept of oligopolistic equilibrium from which we start is easily interpreted in terms of such practices. We then use the common agent multi-principal paradigm as a unified and abstract formulation to describe and parameterize the set of oligopolistic equilibria as they vary in competitive toughness.

Considering an industry producing a group of differentiated products, aggregated through a sub-utility function into a composite commodity, we generalize the concepts of pricing-scheme-equilibrium and of oligopolistic equilibrium defined in previous work (d'Aspremont, Dos Santos Ferreira and Gérard-Varet (1991a,b) and (2003)). This generalization, as we will see, includes the case of a quadratic sub-utility (implying a linear demand to the industry). The cases of perfectly substitutable and of perfectly complementary goods are also covered as limit cases. In the homogeneous product case, the set of oligopolistic equilibria includes (when they exist) the Cournot solution as the enforceable competition regime with minimal competitive toughness, the competitive equilibrium as the one with maximal competitive toughness, and all equilibria corresponding to competition regimes that are intermediate to these two extremes. In the composite good case, the set of enforceable competitive regimes varies with the degree of substitutability but always includes the price and quantity equilibria and may even include (for some intermediate degrees of substitutability) the collusive solution.

These results are all obtained in what Bernheim and Whinston (1986) call the intrinsic case, where contracting has to involve the whole set of competitors. In this intrinsic case, we get a multiplicity of equilibria, but the role of preference separability (through a sub-utility) should be emphasized. In the non-intrinsic case, allowing for exclusive contracting with a single principal, we show that the

\footnotetext{
${ }^{3}$ See e.g. Grether and Plott (1984), Salop (1986), Kalai and Satterthwaite (1986), Holt and Scheffman (1987), Doyle (1988), d'Aspremont, Dos Santos Ferreira and Gérard-Varet (1991a,b).
} 
set of enforceable competitive regimes is usually much reduced, even with preference separability, varying only between monopolistic competition and Bertrand competition.

In the next section (section 2) we define, in a first part, the oligopolistic game and the corresponding concept of oligopolistic equilibrium and, in a second part, an associated auxiliary game that can be interpreted as a common agency game and that has the same set of equilibria. In section 3, the parameterization of the set of (potential) equilibria in terms of competitive toughness is derived from the first order conditions of the auxiliary game. The enforceability of monopolistic competition, of price and quantity competition, and of collusion is examined in this framework. In section 4, we examine the (reduced) set of equilibria one would obtain, first in the non-intrinsic case and then in the case where a global approach would be adopted instead of partial equilibrium approach. Finally, we illustrate the use of our concept of oligopolistic equilibrium and of the corresponding parameterization by referring, in section 5 , to the standard case of symmetric quadratic utility. The conclusion follows.

\section{Oligopolistic and common agency games}

We consider an oligopolistic industry composed by $n$ firms, each firm $i$ producing a specific good with an increasing differentiable cost function $C_{i}($.) defined on $\mathbf{R}_{+}$such that $C_{i}(0)=0$. Each firm $i$ makes offers $\left(p_{i}, q_{i}\right)$ to identical households, which compose a population of unit size aggregated into a representative consumer. We suppose that this offer is made through a sales contract which includes a "meeting competition clause", guaranteeing to a customer some discount if the offer of another firm looks more advantageous, and a "most favored customer clause" excluding price discrimination and, in particular, that the discount be given to one and not to another customer. These "facilitating practices" have already been formalized and analyzed extensively in the homogeneous good case, where different kinds of best price policies are used repeatedly in many industries. What we present here is a formal generalization 
of these clauses to the differentiated product case. But let us characterize, first, the representative consumer's behavior and then turn to the firms programs.

\subsection{The consumer's program}

Adopting a partial equilibrium point of view, the representative consumer is characterized by a separable utility function $U(u(x), z)$, with $x \in \mathbf{R}_{+}^{n}$ and, for simplicity $^{4}, z \in \mathrm{R}_{+}$, a good taken as numeraire. The sub-utility function $u$ is assumed to be increasing and continuous and the utility $U$ to be increasing and strongly quasi-concave (i.e. strictly quasi-concave and twice-differentiable, with a regular bordered Hessian). The sub-utility can be seen as an aggregator function, providing an index of the aggregate consumption in the sector, and can thus be interpreted as the quantity of a composite good. When the goods are perfect substitutes (the homogeneous product case) we let $u(x)=\sum_{i} x_{i}$, and when they are perfect complements we let $u(x)=\min _{i}\left\{x_{i}\right\}$. Outside these two limit cases we assume that $u$ also is strongly quasi-concave.

Because of separability, maximization of $U$ under the budget constraint $p x+$ $z \leq w$, where wealth $w$ does not depend upon prices $p$, can be performed in two stages, corresponding to the choice of the optimal allocation of a given budget $b$, and then of the optimal level of that budget. The first stage program is given by:

$$
\max _{x \in \mathrm{R}_{+}^{n}}\{u(x): p x \leq b\} \equiv v(p, b),
$$

with solutions $X(p, b)=\times_{i} X_{i}(p, b) \in \mathrm{R}_{+}^{n}$, defining (under our assumptions) the Marshallian demand function. At the second stage the consumer determines the budget to be devoted to the $n$-firm industry:

$$
\max _{(b, z) \in \mathrm{R}_{+}^{2}}\{U(v(p, b), z): b+z \leq w\} .
$$

\footnotetext{
${ }^{4}$ This amounts to suppose that the prices of all other goods are fixed throughout, so that $z$ can be treated as the quantity of a Hicksian composite good.
} 
For simplicity of notation, we omit reference to the variable $w$, assumed fixed throughout in our partial equilibrium analysis, and denote $B(p)$ the solution in $b$ of problem (2). The function $D(p) \equiv X(p, B(p))$ is called the Walrasian demand function.

Alternatively, the consumer problem can be decomposed into two different stages, corresponding to the choice of the expenditure minimizing allocation ensuring a given sub-utility level $\underline{u}$, and then of the optimal sub-utility level. The first stage becomes:

$$
\min _{x \in \mathrm{R}_{+}^{n}}\{p x: u(x) \geq \underline{u}\} \equiv e(p, \underline{u}),
$$

with solutions $H(p, \underline{u})=\times_{i} H_{i}(p, \underline{u}) \in \mathbf{R}_{+}^{n}$, defining the Hicksian demand function. The corresponding first order conditions are given by

$$
p_{i}=\partial_{u} e(p, \underline{u}) \partial_{i} u(x) .
$$

At the second stage, the consumer's program is now

$$
\max _{(\underline{u}, z) \in \mathrm{R}_{+}^{2}}\{U(\underline{u}, z): e(p, \underline{u})+z \leq w\},
$$

with the solution in $\underline{u}$ denoted $\bar{D}(p)$ and interpreted as the demand for the aggregate good. We assume that $\bar{D}$ is decreasing (the composite good produced in the sector is not a Giffen good). As well known, these different demand functions are related by duality:

$$
H(p, \bar{D}(p))=X(p, e(p, \bar{D}(p)))=D(p) .
$$

\subsection{The oligopolistic game}

For each good $i$, solving in $p_{i}$ the first order condition (4) at $\underline{u}=u\left(q_{i}, q_{-i}\right)$, delivers the maximal unit price $\psi_{i}\left(p_{-i}, q_{i}, q_{-i}\right)$ the consumer would be willing to pay for quantity $q_{i}$ given the other firms prices and quantitites. This price is uniquely defined, as can be readily seen by referring to the equivalent condition

$$
q_{i}=H_{i}\left(p_{i}, p_{-i}, u\left(q_{i}, q_{-i}\right)\right),
$$


where $H_{i}$ is decreasing in $p_{i}$. In the homogeneous good limit case we have $u(q)=$ $\sum_{j} q_{j}$ and $e(p, u)=\left[\min _{j}\left\{p_{j}\right\}\right] u$ so that $\partial_{u} e\left(p_{i}, p_{-i}, u\left(q_{i}, q_{-i}\right)\right) \partial_{i} u\left(q_{i}, q_{-i}\right)=$ $\min \left\{p_{i}, \psi_{i}\left(p_{-i}, q_{i}, q_{-i}\right)\right\}$ with $\psi_{i}\left(p_{-i}, q_{i}, q_{-i}\right)=\min _{j \neq i}\left\{p_{j}\right\}$, a formal way to introduce a "meeting competition clause" in the sales contract. In the more general differentiated good case, such a clause can be generalized leading to the following payoff of firm $i$

$$
\Pi_{i}^{O}\left(p_{i}, p_{-i}, q_{i}, q_{-i}\right)=\min \left\{p_{i}, \psi_{i}\left(p_{-i}, q_{i}, q_{-i}\right)\right\} q_{i}-C_{i}\left(q_{i}\right) .
$$

But, to specify completely the oligopolistic game we need to refer to the upper bound imposed on $u(q)$ by the demand to the industry $\bar{D}(p)$ : each firm $i$ thus chooses a strategy $\left(p_{i}, q_{i}\right)$ in $\mathbf{R}_{+}^{2}$ to obtain:

$$
\begin{aligned}
\Pi_{i}^{O}\left(p_{i}, p_{-i}, q_{i}, q_{-i}\right)= & \min \left\{p_{i}, \psi_{i}\left(p_{-i}, q_{i}, q_{-i}\right)\right\} q_{i}-C_{i}\left(q_{i}\right), \\
& \text { if } u\left(q_{i}, q_{-i}\right) \leq \bar{D}\left(p_{i}, p_{-i}\right), \\
= & -C_{i}\left(q_{i}\right), \text { otherwise. }
\end{aligned}
$$

We say that a Nash equilibrium $\left(p^{*}, q^{*}\right)$ of the oligopolistic game is an oligopolistic equilibrium if it satisfies the additional requirement that the consumer is not rationed:

$$
u\left(q^{*}\right)=\bar{D}\left(p^{*}\right) .
$$

\subsection{The common agency game}

We shall not study the oligopolistic game and its set of equilibria directly. Instead, we introduce an "auxiliary game" which will be shown to be equivalent to the oligopolistic game, in the sense of having the same set of equilibria. It is this auxiliary game that can be viewed as a multi-principal common agency game. In the auxiliary game each firm $i$ still selects offers $\left(p_{i}, q_{i}\right)$ in $\mathbf{R}_{+}^{2 n}$, and has payoff

$$
\begin{aligned}
& \Pi_{i}^{A}\left(p_{i}, p_{-i}, q_{i}, q_{-i}\right)=p_{i} q_{i}-C_{i}\left(q_{i}\right) \\
& \text { if } q_{i} \leq H_{i}\left(p_{i}, p_{-i}, u\left(q_{i}, q_{-i}\right)\right) \text { and } e\left(p_{i}, p_{-i}, u\left(q_{i}, q_{-i}\right)\right) \leq B\left(p_{i}, p_{-i}\right), \\
& \Pi_{i}^{A}\left(p_{i}, p_{-i}, q_{i}, q_{-i}\right)=-C_{i}\left(q_{i}\right), \text { otherwise. }
\end{aligned}
$$


This game can be interpreted as a common agency game between the firms acting as principals. In this interpretation, offering sales contracts to the consumers (viz. through the web) has to be seen as a possibility given to the firms in addition to simply supplying their outputs, at chosen prices, in the market place. From the consumer point of view, the advantage of contracting over searching in the market place is to reduce transaction costs (although, for simplicity, these are not explicitly introduced in this analysis). The objective of each firm $i$ is to offer a contract maximizing profit under the condition of being acceptable by the consumer. This condition is standardly formalised by two constraints, an "incentive compatibility" constraint and a "participation constraint". The incentive compatibility constraint is meant to ensure that the contract is compatible with the consumer expenditure minimizing behavior. It requires that the contracted quantity $q_{i}$ by firm $i$ does not exceed what the consumer would be ready to consume at prices $p$, in order to obtain the sub-utility $u(q)$ entailed by the set of contracts. Remembering the definition of the Hicksian demand, this is precisely the first constraint appearing in the definition of the auxiliary game:

$$
q_{i} \leq H_{i}\left(p_{i}, p_{-i}, u\left(q_{i}, q_{-i}\right)\right)
$$

of which the dual version, based on the first order condition (4) and the definition of $\psi_{i}$, is:

$$
p_{i} \leq \min \left\{p_{i}, \psi_{i}\left(p_{-i}, q_{i}, q_{-i}\right)\right\} .
$$

Following our story, the participation constraint is introduced to ensure that the consumer would rather accept the contract offered by the firms rather than go to the market place. So, participation requires that the minimal expenditure associated with the proposed contracts (assumed to be incentive compatible) does not exceed the budget optimally allocated to the industry by the consumer. This is the second constraint in the auxiliary game:

$$
e\left(p_{i}, p_{-i}, u\left(q_{i}, q_{-i}\right)\right) \leq B\left(p_{i}, p_{-i}\right) .
$$


At a Nash equilibrium $\left(p^{*}, q^{*}\right)$ of the auxiliary game, this constraint (the same imposed to every firm at any deviation) combined with all the incentive compatibility constraints implies a stronger participation condition, satisfied by the equilibrium contracts themselves:

$$
\sum_{i=1}^{n} p_{i}^{*} q_{i}^{*} \leq \sum_{i=1}^{n} p_{i}^{*} H_{i}\left(p^{*}, u\left(q^{*}\right)\right)=e\left(p^{*}, u\left(q^{*}\right)\right) \leq B\left(p^{*}\right) .
$$

In fact, we want to reinforce this condition and call $\left(p^{*}, q^{*}\right)$ a common agency equilibrium if it is a Nash equilibrium of the auxiliary game and satisfies the additional (no-rationing) requirement

$$
q_{i}^{*}=H_{i}\left(p^{*}, u\left(q^{*}\right)\right)=X_{i}\left(p^{*}, B\left(p^{*}\right)\right), i=1, \ldots, n,
$$

which implies that (14) holds as a set of equalities.

The following proposition shows that the oligopolistic game and the auxiliary game are equivalent:

Proposition 1 A vector of singleton contracts $\left(p^{*}, q^{*}\right) \in \mathbf{R}_{+}^{2 n}$ is an oligopolistic equilibrium if and only if it is a common agency equilibrium.

Proof. We can first check that the two restrictions (9) and (15) are equivalent when $\left(p^{*}, q^{*}\right)$ is a Nash equilibrium of the two games. Clearly $u\left(q^{*}\right)=$ $\bar{D}\left(p^{*}\right)$ is equivalent to $H\left(p^{*}, u\left(q^{*}\right)\right)=H\left(p^{*}, \bar{D}\left(p^{*}\right)\right)=X\left(p^{*}, B\left(p^{*}\right)\right)$, by duality. Moreover, if $q_{i}^{*}<H_{i}\left(p^{*}, u\left(q^{*}\right)\right)$ for some $i$, then by strict monotonicity of $u\left(\right.$ and since $\left.q^{*} \leq H\left(p^{*}, u\left(q^{*}\right)\right)\right), u\left(q^{*}\right)<u\left(H\left(p^{*}, u\left(q^{*}\right)\right)\right)=u\left(q^{*}\right)$, a contradiction. So $q^{*}=H\left(p^{*}, u\left(q^{*}\right)\right)$ and

$$
p_{i}^{*}=\psi_{i}\left(p_{-i}^{*}, q_{i}^{*}, q_{-i}^{*}\right), \text { for all } i .
$$

Now, take a Nash equilibrium $\left(p^{*}, q^{*}\right)$ of the common agency game and suppose that there exists, for some firm $i$, a deviation in the oligopolistic game, that is, an offer $\left(p_{i}, q_{i}\right)$ such that $u\left(q_{i}, q_{-i}^{*}\right) \leq \bar{D}\left(p_{i}, p_{-i}^{*}\right)$ and $\Pi_{i}^{O}\left(p_{i}, p_{-i}^{*}, q_{i}, q_{-i}^{*}\right)>$ $\Pi_{i}^{O}\left(p^{*}, q^{*}\right)$. If we let

$$
p_{i}^{\prime}=\min \left\{p_{i}, \psi_{i}\left(p_{-i}^{*}, q_{i}, q_{-i}^{*}\right)\right\},
$$


then the definition of $\psi_{i}$, the equilibrium relation (16) and the equivalence of (12) and (11) imply:

$$
\begin{aligned}
p_{i}^{\prime} q_{i}-C_{i}\left(q_{i}\right) & =\Pi_{i}^{O}\left(p_{i}, p_{-i}^{*}, q_{i}, q_{-i}^{*}\right)>\Pi_{i}^{O}\left(p^{*}, q^{*}\right)=p_{i}^{*} q_{i}^{*}-C_{i}\left(q_{i}^{*}\right), \\
\text { and } q_{i} & \leq H_{i}\left(p_{i}^{\prime}, p_{-i}^{*}, u\left(q_{i}, q_{-i}^{*}\right)\right) .
\end{aligned}
$$

In addition, since $p_{i}^{\prime} \leq p_{i}$ (so that $\bar{D}\left(p_{i}, p_{-i}^{*}\right) \leq \bar{D}\left(p_{i}^{\prime}, p_{-i}^{*}\right)$ ), we get

$$
e\left(p_{i}^{\prime}, p_{-i}^{*}, u\left(q_{i}, q_{-i}^{*}\right)\right) \leq e\left(p_{i}^{\prime}, p_{-i}^{*}, \bar{D}\left(p_{i}^{\prime}, p_{-i}^{*}\right)\right)=B\left(p_{i}^{\prime}, p_{-i}^{*}\right) .
$$

Hence $\left(p_{i}^{\prime}, q_{i}\right)$ satisfies the two constraints of the common agency game and we get a contradiction. Therefore $\left(p^{*}, q^{*}\right)$ must be a Nash equilibrium of the oligopolistic game.

To prove the converse, suppose $\left(p^{*}, q^{*}\right)$ is a Nash equilibrium of the oligopolistic game and that, for some $i$ and some contract $\left(p_{i}, q_{i}\right)$ satisfying the two constraints (12) and (13), we have: $p_{i} q_{i}-C_{i}\left(q_{i}\right)>p_{i}^{*} q_{i}^{*}-C_{i}\left(q_{i}^{*}\right)$. By (13) and the equality $B(p)=e(p, \bar{D}(p))$, we get $u\left(q_{i}, q_{-i}^{*}\right) \leq \bar{D}\left(p_{i}, p_{-i}^{*}\right)$. Also, by definition,

$$
p_{i}=\min \left\{p_{i}, \psi_{i}\left(p_{-i}^{*}, q_{i}, q_{-i}^{*}\right)\right\}
$$

and the result follows by contradiction.

\section{Parameterization of the set of equilibria}

The equivalence between the oligopolistic game and the common agency game is not only of conceptual interest. It can be used to investigate and parameterize the set of oligopolistic equilibria. If we look at the definition of a common agency equilibrium, each firm $i$ equilibrium strategy should solve a canonical program of the following type:

$$
\max _{\left(p_{\mathrm{i}}, q_{\mathrm{i}}\right) \in \mathrm{R}_{+}^{2}}\left\{p_{i} q_{i}-C_{i}\left(q_{i}\right): f_{i}\left(p_{i}, p_{-i}^{*}, q_{i}, q_{-i}^{*}\right) \leq 1 \text { and } g_{i}\left(p_{i}, p_{-i}^{*}, q_{i}, q_{-i}^{*}\right) \leq 1\right\},
$$


where the constraint on $f_{i}$ refers to the incentive compatibility constraint and the one on $g_{i}$ to the appropriate participation constraint. Associating with these constraints the multipliers $\phi_{i}$ and $\gamma_{i}$, respectively, and using the normalization $\theta_{i} \equiv \phi_{i} /\left(\phi_{i}+\gamma_{i}\right) \in[0,1]$, the first order conditions can be written in terms of the Lerner index of degree of monopoly $\mu_{i}^{*}$ as measured at equilibrium:

$$
\mu_{i}^{*} \equiv \frac{p_{i}^{*}-C_{i}^{\prime}\left(q_{i}^{*}\right)}{p_{i}^{*}}=\frac{\theta_{i} \epsilon_{q_{\mathrm{i}}} f_{i}\left(p^{*}, q^{*}\right)+\left(1-\theta_{i}\right) \epsilon_{q_{\mathrm{i}}} g_{i}\left(p^{*}, q^{*}\right)}{\theta_{i} \epsilon_{p_{\mathrm{i}}} f_{i}\left(p^{*}, q^{*}\right)+\left(1-\theta_{i}\right) \epsilon_{p_{\mathrm{i}}} g_{i}\left(p^{*}, q^{*}\right)},
$$

where $\epsilon$ denotes the elasticity operator. The normalized multipliers $\theta \in[0,1]^{n}$ will serve to parameterize the set of equilibria. Of course, this does not mean that, for every value of $\theta$, an equilibrium exists. This set is only the set of potential equilibria, existence depending on the fundamentals of the economy.

\subsection{The set of potential equilibria}

Applying the canonical formulation to the common agency game, firm $i$ program can be written as

$$
\begin{aligned}
& \max _{\left(p_{i}, q_{\mathrm{i}}\right) \in \mathrm{R}_{+}^{2}} p_{i} q_{i}-C_{i}\left(q_{i}\right) \\
& \text { s.t. } \frac{q_{i}}{H_{i}\left(p_{i}, p_{-i}^{*}, u\left(q_{i}, q_{-i}^{*}\right)\right)} \leq 1 \text { and } \frac{e\left(p_{i}, p_{-i}^{*}, u\left(q_{i}, q_{-i}^{*}\right)\right)}{B\left(p_{i}, p_{-i}^{*}\right)} \leq 1 .
\end{aligned}
$$

Observe that the first constraint bounds firm $i$ deviations by the competitive pressure coming from its competitors within the industry, whereas the second constraint refers to the possibility for the consumers to spend outside the industry. Accordingly, the normalized multiplier $\theta_{i}$, expressing the implicit relative value for firm $i$ of relaxing the first constraint, can be interpreted as a measure of the relative competitive toughness of firm $i$ within the industry, at the equilibrium $\left(p^{*}, q^{*}\right)$.

Before applying formula (17) to each firm $i$ program, we introduce some simplifying notation. At equilibrium $\left(p^{*}, q^{*}\right)$, we shall denote the budget share of good $i$

$$
\alpha_{i}^{*} \equiv \frac{p_{i}^{*} q_{i}^{*}}{e\left(p^{*}, u\left(q^{*}\right)\right)}=\epsilon_{p_{\mathrm{i}}} e\left(p^{*}, u\left(q^{*}\right)\right)=\epsilon_{q_{\mathrm{i}}} e\left(p^{*}, u\left(q^{*}\right)\right),
$$


which (by Shephard's lemma and the first order condition (4)) is also the elasticity with respect to either $p_{i}$ or $q_{i}$ of the minimal expenditure for getting $u\left(q^{*}\right)$ at prices $p^{*}$. We also want to use the elasticity with respect to $p_{i}$ of the corresponding marginal expenditure $\partial_{u} e\left(p^{*}, u\left(q^{*}\right)\right)$, which is also the elasticity with respect to $q_{i}$ of the Hicksian demand: ${ }^{5}$

$$
\varepsilon_{i}^{*} \equiv \epsilon_{p_{\mathrm{i}}} \partial_{u} e\left(p^{*}, u\left(q^{*}\right)\right)=\epsilon_{q_{\mathrm{i}}} H_{i}\left(p^{*}, u\left(q^{*}\right)\right) .
$$

Now, when considering the consequences for firm $i$ of deviating from equilibrium $\left(p^{*}, q^{*}\right)$ in price $p_{i}$, we have to distinguish two channels of influence. First, there is the impact on its market share $H_{i}\left(p_{i}, p_{-i}^{*}, u\left(q^{*}\right)\right) / u\left(q^{*}\right)$ of a change in the relative price $p_{i} / \partial_{u} e\left(p_{i}, p_{-i}^{*}, u\left(q^{*}\right)\right)$ as measured by the absolute value of the corresponding elasticity, that is, of the elasticity of substitution of good $i$ for the composite good produced in the industry, which, by (20), is also equal to the absolute value of the elasticity of $q_{i}$ with respect to $p_{i}$ along the curve representing the incentive compatibility constraint:

$$
\begin{aligned}
s_{i}^{*} & \equiv s_{i}\left(p^{*}, u\left(q^{*}\right)\right) \equiv-\frac{\epsilon_{p_{\mathrm{i}}} H_{i}\left(p^{*}, u\left(q^{*}\right)\right)}{1-\epsilon_{p_{\mathrm{i}}} \partial_{u} e\left(p^{*}, u\left(q^{*}\right)\right)} \\
& =-\frac{\epsilon_{p_{\mathrm{i}}} H_{i}\left(p^{*}, u\left(q^{*}\right)\right)}{1-\varepsilon_{i}^{*}}=-\left.\frac{d q_{i}}{d p_{i}} \frac{p_{i}}{q_{i}}\right|_{q_{\mathrm{i}}=H_{\mathrm{i}}\left(p_{\mathrm{i}}, p_{-\mathrm{i}}^{*}, u\left(q_{\mathrm{i}}, q_{-\mathrm{i}}^{*}\right)\right)} .
\end{aligned}
$$

This elasticity of substitution can be also computed using the dual version of the incentive compatibility constraint.

$$
\begin{aligned}
s_{i}^{*} & =-\left.\frac{d q_{i}}{d p_{i}} \frac{p_{i}}{q_{i}}\right|_{p_{\mathrm{i}}=\partial_{u} e\left(p_{\mathrm{i}}, p_{-\mathrm{i}}^{*}, u\left(q_{\mathrm{i}}, q_{-\mathrm{i}}^{*}\right)\right) \partial_{\mathrm{i}} u\left(q_{\mathrm{i}}, q_{-\mathrm{i}}^{*}\right)} \\
& =\frac{1-\varepsilon_{i}^{*}}{-\epsilon_{u} \partial_{u} e\left(p^{*}, u\left(q^{*}\right)\right) \epsilon_{i} u\left(q^{*}\right)-\epsilon_{i} \partial_{i} u\left(q^{*}\right)} .
\end{aligned}
$$

The second channel of influence is through the change in demand $\bar{D}\left(p_{i}, p_{-i}^{*}\right)$ for the composite good produced in the industry. Taking $e\left(p^{*}, \cdot\right)$ as a quantity

\footnotetext{
${ }^{5}$ By Shephard's lemma and the first order condition (4) we have:

$$
\partial_{u} H_{i}\left(p^{*}, u\left(q^{*}\right)\right) \partial_{i} u\left(q^{*}\right)=\frac{\partial_{p_{\mathrm{i}} u}^{2} e\left(p^{*}, u\left(q^{*}\right)\right) p_{i}^{*}}{\partial_{u} e\left(p^{*}, u\left(q^{*}\right)\right)} .
$$
}


index of this good, and $e\left(\cdot, u\left(q^{*}\right)\right)$ as the corresponding price index, we may accordingly compute the absolute value of the elasticity of demand to the industry via good $i$ as follows:

$$
\begin{aligned}
\sigma_{i}^{*} & \equiv \sigma_{i}\left(p^{*}, u\left(q^{*}\right)\right) \equiv-\frac{\epsilon_{u} e\left(p^{*}, \bar{D}\left(p^{*}\right)\right) \epsilon_{p_{\mathrm{i}}} \bar{D}\left(p^{*}\right)}{\epsilon_{p_{\mathrm{i}}} e\left(p^{*}, u\left(q^{*}\right)\right)} \\
& =-\frac{\epsilon_{u} e\left(p^{*}, \bar{D}\left(p^{*}\right)\right) \epsilon_{p_{\mathrm{i}}} \bar{D}\left(p^{*}\right)}{\alpha_{i}^{*}}=-\left.\frac{d q_{i}}{d p_{i}} \frac{p_{i}}{q_{i}}\right|_{u\left(q_{\mathrm{i}}, q_{-\mathrm{i}}^{*}\right)=\bar{D}\left(p_{\mathrm{i}}, p_{-\mathrm{i}}^{*}\right)} .
\end{aligned}
$$

This is also equal to the absolute value of the elasticity of $q_{i}$ with respect to $p_{i}$ along the curve representing the participation constraint: ${ }^{6}$

$$
\begin{aligned}
\sigma_{i}^{*} & =-\left.\frac{d q_{i}}{d p_{i}} \frac{p_{i}}{q_{i}}\right|_{e\left(p_{\mathrm{i}}, p_{-i}^{*}, u\left(q_{\mathrm{i}}, q_{-\mathrm{i}}^{*}\right)\right)=B\left(p_{\mathrm{i}}, p_{-\mathrm{i}}^{*}\right)} \\
& =\frac{\epsilon_{p_{\mathrm{i}}} e\left(p^{*}, u\left(q^{*}\right)\right)-\epsilon_{p_{\mathrm{i}}} B\left(p^{*}\right)}{\epsilon_{q_{\mathrm{i}}} e\left(p^{*}, u\left(q^{*}\right)\right)}=1-\frac{\epsilon_{p_{\mathrm{i}}} B\left(p^{*}\right)}{\alpha_{i}^{*}},
\end{aligned}
$$

using (19).

This notation allows us to translate formula (17) and get a simple expression for the equilibrium value $\mu_{i}^{*}$ of each firm $i$ degree of monopoly:

$$
\mu_{i}^{*}=\frac{\theta_{i}\left(1-\varepsilon_{i}^{*}\right)+\left(1-\theta_{i}\right) \alpha_{i}^{*}}{\theta_{i}\left(1-\varepsilon_{i}^{*}\right) s_{i}^{*}+\left(1-\theta_{i}\right) \alpha_{i}^{*} \sigma_{i}^{*}} .
$$

At one extreme, considering the maximal values $\theta_{i}=1$, for all $i$, meaning maximal relative competitive toughness, we get the first order conditions

$$
\mu_{i}^{*}=\frac{1}{s_{i}^{*}}
$$

Each firm degree of monopoly is equal to the inverse of the elasticity of substitution of $q_{i}$ for $\underline{u}$, a requirement which coincides with the condition one would obtain if the budget share $\alpha_{i}^{*}$ of each firm $i$ were decreased towards 0 (say, by letting the number of firms increase indefinitely). This situation can thus be assimilated to monopolistic competition. At the other extreme, when all $\theta_{i}=0$,

\footnotetext{
${ }^{6}$ Notice indeed that$$
\frac{\partial_{i} u\left(q^{*}\right) q_{i}^{*}}{u\left(q^{*}\right)}=\frac{p_{i}^{*} q_{i}^{*} / e\left(p^{*}, u\left(q^{*}\right)\right)}{\partial_{u} e\left(p^{*}, u\left(q^{*}\right)\right) u\left(q^{*}\right) / e\left(p^{*}, u\left(q^{*}\right)\right)}=\frac{\alpha_{i}^{*}}{\epsilon_{u} e\left(p^{*}, u\left(q^{*}\right)\right)},
$$$$
\text { with } u\left(q^{*}\right)=\bar{D}\left(p^{*}\right) \text {. }
$$ 
competitive toughness is minimal and the first order conditions become

$$
\mu_{i}^{*}=\frac{1}{\sigma_{i}^{*}},
$$

coinciding with the conditions that would result from having the price elasticity $\varepsilon_{i}^{*}$ of the marginal expenditure increase towards 1 . Each firm degree of monopoly is then equal to the inverse of the elasticity of demand to the industry via good $i$. When it exists, the equilibrium thus characterized corresponds to the collusive solution, which amounts to solve

$$
\max _{(p, q) \in \mathrm{R}_{+}^{2 n}}\left\{e(p, u(q))-\sum_{i} C_{i}\left(q_{i}\right): e(p, u(q)) \leq B(p)\right\} .
$$

A particular case is the the case of homothetic sub-utility by taking the function $u($.$) to be homogeneous of degree one. Then, for some nonnegative$ index $P$, homogeneous of degree one and increasing in $p$, we obtain $v(p, b)=$ $b / P(p), e(p, u(q))=P(p) u(q)$, so that $\partial_{u} e(p, u(q)) \partial_{i} u(q)=P(p) \partial_{i} u(q)$ and $B(p)=\widehat{B}(P(p))$. Also we let $\widehat{D}(P(p)) \equiv \widehat{B}(P(p)) / P(p)$ denote the Walrasian demand for the composite good and assume $\widehat{D}$ is strictly decreasing in $P$. By Shephard's lemma, $H_{i}(p, u(q))=\partial_{i} P(p) u(q)$, so that the incentive compatibility constraint can be written as a constraint on the market share $q_{i} / u(q)$ of firm $i$ and the participation constraint for the intrinsic game as a constraint on the market size $u(q)$. More precisely, the constraints (18) of each firm $i$ program become ${ }^{7}$ :

$$
\frac{1}{\partial_{i} P\left(p_{i}, p_{-i}^{*}\right)} \frac{q_{i}}{u\left(q_{i}, q_{-i}^{*}\right)} \leq 1 \text { and } \frac{1}{\widehat{D}\left(P\left(p_{i}, p_{-i}^{*}\right)\right)} u\left(q_{i}, q_{-i}^{*}\right) \leq 1 .
$$

Applying formula (26) and using the fact that, in this case, $\alpha_{i}^{*}=\varepsilon_{i}^{*}$ and $\sigma_{i}^{*}=-\epsilon \widehat{D}\left(P\left(p^{*}\right)\right) \equiv \sigma^{*}$, the degree of monopoly of firm $i$, at an equilibrium

\footnotetext{
${ }^{7}$ Using the first order condition for the consumer expenditure minimization, $p_{i}=$ $P(p) \partial_{i} u(x)$, the constraints can be written alternatively as an inequality on the relative price $p_{i} / P(p)$ and an inequality on the price index $P(p)$ :
}

$$
\frac{1}{\partial_{i} u\left(q_{i}, q_{-i}^{*}\right)} \frac{p_{i}}{P\left(p_{i}, p_{-i}^{*}\right)} \leq 1 \text { and } \frac{1}{D^{-1}\left(u\left(q_{i}, q_{-i}^{*}\right)\right)} P\left(p_{i}, p_{-i}^{*}\right) \leq 1 \text {. }
$$


$\left(p^{*}, q^{*}\right)$, has to satisfy ${ }^{8}$ :

$$
\mu_{i}^{*}=\frac{\theta_{i}\left(1-\alpha_{i}^{*}\right)+\left(1-\theta_{i}\right) \alpha_{i}^{*}}{\theta_{i}\left(1-\alpha_{i}^{*}\right) s_{i}^{*}+\left(1-\theta_{i}\right) \alpha_{i}^{*} \sigma^{*}} .
$$

Thus, $\mu_{i}^{*}$ is the harmonic mean of $1 / s_{i}^{*}$ and $1 / \sigma^{*}$ weighted, respectively, by $\theta_{i}\left(1-\alpha_{i}^{*}\right)$ and $\left(1-\theta_{i}\right) \alpha_{i}^{*}$.

When the elasticity of substitution increases to $\infty$, or decreases to 0 , the softest enforceable competition regime converges to one of the two well-known Cournot solutions, one for homogeneous oligopoly and the other for complementary monopoly, respectively. Indeed, when the industry goods are perfect substitutes, the Hicksian demand correspondence satisfies $H_{i}(p, \underline{u})=[0, \underline{u}]$ if $p_{i}=\min _{j}\left\{p_{j}\right\}, H_{i}(p, \underline{u})=\{0\}$ otherwise. Therefore, the incentive compatibility constraint of firm $i$ at some equilibrium $\left(p^{*}, q^{*}\right)$ reduces to

$$
p_{i} \leq \min _{j \neq i}\left\{p_{j}^{*}\right\} .
$$

As to the participation constraint, it can be expressed for the intrinsic common agency game as

$$
p_{i} \leq \widehat{D}^{-1}\left(q_{i}+\sum_{j \neq i} q_{j}^{*}\right),
$$

assuming a decreasing market demand function $\widehat{D}$, and requiring that the quantity contracted by all firms is less than or equal to the market demand. Applying formula (17) once again (with the constraints reformulated in canonical form), we obtain firm $i$ degree of monopoly

$$
\mu_{i}^{*}=\left(1-\theta_{i}\right) \frac{\alpha_{i}^{*}}{\sigma^{*}}
$$

parameterized $^{9}$ in $\theta_{i} \in[0,1]$. Letting the $\theta_{i}$ 's vary from 0 to 1 , we get the

\footnotetext{
${ }^{8} \mathrm{By}$ formula (17) we get, from the first order conditions of the alternative formulation of the firm program, as presented in the preceding footnote, an alternative parameterization:

$$
\mu_{i}^{*}=\frac{\theta_{i}^{\prime}\left(1-\alpha_{i}^{*}\right)\left(1 / s_{i}^{*}\right)+\left(1-\theta_{i}^{\prime}\right) \alpha_{i}^{*}\left(1 / \sigma^{*}\right)}{\theta_{i}^{\prime}\left(1-\alpha_{i}^{*}\right)+\left(1-\theta_{i}^{\prime}\right) \alpha_{i}^{*}}
$$

the arithmetic mean of $1 / s_{i}^{*}$ and $1 / \sigma^{*}$ weighted by $\theta_{i}^{\prime}\left(1-\alpha_{i}^{*}\right)$ and $\left(1-\theta_{i}^{\prime}\right) \alpha_{i}^{*}$, respectively.

${ }^{9} \mathrm{We}$ could have re-formulated the problem in such way that any admissible $\theta_{i}^{\prime}$ varies between $1 / 2$ (Cournot) and 1 (perfect competition), in line with the alternative parameterization of the homothetic case given in the preceding footnote (see d'Aspremont et al., 2003).
} 
outcomes for all intermediate regimes, characterized by increasing competitive toughness, between Cournot and perfect competition. In particular, collusion is not enforceable, as well-known since Cournot: any price above the Cournot price would trigger a downward price deviation.

The other limit case, where goods are perfect complements, can be treated symmetrically, using instead (11). We then have $u(q)=\min _{j}\left\{q_{j}\right\}$ and, letting $\bar{P}(p)=\sum_{j} p_{j}$, we obtain $e(p, u(q))=\bar{P}(p) u(q)$, leading to the constant Hicksian demand $H_{i}(p, u(q))=u(q)$.

Therefore, the incentive compatibility constraint of firm $i$ at some equilibrium $\left(p^{*}, q^{*}\right)$ reduces to

$$
q_{i} \leq \min _{j \neq i}\left\{q_{j}^{*}\right\}
$$

This could be interpreted as a clause releasing the consumer from the obligation of useless purchasing. Referring again to the market demand function $\widehat{D}(\bar{P}(p)) \equiv \widehat{B}(\bar{P}(p)) / \bar{P}(p)$ assumed decreasing, the participation constraint in the intrinsic case becomes

$$
q_{i} \leq \widehat{D}\left(p_{i}+\sum_{j \neq i} p_{j}^{*}\right) .
$$

Because of duality with respect to the perfect substitutability case ${ }^{10}$, we can perform a similar argument as in the preceding subsection (applying formula (17)) and obtain the degree of monopoly of firm $i$ at some equilibrium $\left(p^{*}, q^{*}\right)$ :

$$
\mu_{i}^{*}=\frac{1}{\left(1-\theta_{i}\right) \alpha_{i}^{*} \sigma^{*}} .
$$

Letting the $\theta_{i}$ 's increase from 0 to their highest values such that the $\mu_{i}$ 's are kept smaller than 1 (and the prices finite), we get the outcomes for all regimes, characterized by increasing competitive toughness. The Cournot (1838, ch. IX) complementary monopoly equilibrium, ${ }^{11}$ the dual to homogeneous oligopoly

\footnotetext{
${ }^{10}$ See Sonnenschein (1968).

${ }^{11}$ The complementary monopoly equilibrium is a price equilibrium $p^{*}$ solving for each $i$

$$
\max _{p_{\mathrm{i}}}\left[p_{i} \widehat{D}\left(p_{i}+\sum_{j \neq i} p_{j}^{*}\right)-C_{i}\left(\widehat{D}\left(p_{i}+\sum_{j \neq i} p_{j}^{*}\right)\right)\right] .
$$
}


equilibrium, also corresponds to minimal toughness $\left(\theta_{i}=0\right.$ for all $\left.i\right)$. Collusion is again not enforceable.

\subsection{Price and quantity equilibria}

Coming back to the general composite good case, we may look at two intermediate equilibrium concepts, the price and the quantity equilibrium. The first order conditions of a price equilibrium, namely of the solution to the following program for each firm $i$

$$
\max _{p_{\mathrm{i}} \in \mathrm{R}_{+}}\left\{p_{i} D_{i}\left(p_{i}, p_{-i}^{*}\right)-C_{i}\left(D_{i}\left(p_{i}, p_{-i}^{*}\right)\right)\right\}
$$

lead $^{12}$ to

$$
\mu_{i}^{*}=-\frac{1}{\epsilon_{p_{\mathrm{i}}} D_{i}\left(p^{*}\right)}=\frac{1}{\left(1-\varepsilon_{i}^{*}\right) s_{i}^{*}+\varepsilon_{i}^{*} \sigma_{i}^{*}},
$$

which could be directly obtained from the general formula (26) by taking the competitive toughness

$$
\theta_{i}=\frac{\alpha_{i}^{*}}{\alpha_{i}^{*}+\varepsilon_{i}^{*}}
$$

At an oligopolistic equilibrium corresponding to a price equilibrium, each firm $i$ degree of monopoly is thus equal to the harmonic mean of $1 / s_{i}^{*}$ and $1 / \sigma_{i}^{*}$, with weights respectively equal to $1-\varepsilon_{i}^{*}$ and $\varepsilon_{i}^{*}$.

It is easy to show that $\left(p^{*}, q^{*}\right)$, with $q_{i}^{*}=\widehat{D}\left(\sum_{j} p_{j}^{*}\right)$ for all $i$, is an equilibrium of the intrinsic common agency game. Otherwise, some firm $i$ would be able, through some choice $\left(p_{i}, q_{i}\right) \in$ $\mathrm{R}_{+}^{2}$, satisfying the incentive and participation constraints, to get a profit $p_{i} q_{i}-C_{i}\left(q_{i}\right)>p_{i}^{*} q_{i}^{*}-$ $C_{i}\left(q_{i}^{*}\right)$. Take $p_{i}^{\prime} \geq p_{i}$ such that $q_{i}=\widehat{D}\left(p_{i}^{\prime}+\sum_{j \neq i} p_{j}^{*}\right)$. Then, $p_{i}^{\prime} q_{i}-C_{i}\left(q_{i}\right)>p_{i}^{*} q_{i}^{*}-C_{i}\left(q_{i}^{*}\right)$, implying that $p_{i}^{\prime}$ is a deviation to Cournot's complementary monopoly solution.

${ }^{12}$ Using $D_{i}(p) \equiv X_{i}(p, B(p)) \equiv H_{i}(p, v(p, B(p)))$, the Slutsky equation, the relations (19), (20), (21) and (25), and the equality $\partial_{b} v(p, b)=1 / \partial_{u} e(p, v(p, b))$, we get

$$
\begin{array}{r}
\epsilon_{i} D_{i}\left(p^{*}\right)=\epsilon_{p_{\mathrm{i}}} X_{i}\left(p^{*}, B\left(p^{*}\right)\right)+\epsilon_{b} X_{i}\left(p^{*}, B\left(p^{*}\right)\right) \epsilon_{i} B\left(p^{*}\right) \\
=\epsilon_{p_{\mathrm{i}}} H_{i}\left(p^{*}, v\left(p^{*}, B\left(p^{*}\right)\right)\right)-\epsilon_{b} X_{i}\left(p^{*}, B\left(p^{*}\right)\right)\left(\frac{p_{i}^{*} D_{i}\left(p^{*}\right)}{B\left(p^{*}\right)}-\epsilon_{i} B\left(p^{*}\right)\right) \\
=-\left(1-\varepsilon_{i}^{*}\right) s_{i}^{*}-\left[\varepsilon_{i}^{*} / \alpha_{i}^{*}\right] \alpha_{i}^{*} \sigma_{i}^{*} .
\end{array}
$$


Consider now a quantity equilibrium, namely a solution $q^{*}$ to the following program for each firm $i$

$$
\max _{q_{\mathrm{i}} \in \mathrm{R}_{+}}\left\{\left(D^{-1}\right)_{i}\left(q_{i}, q_{-i}^{*}\right) q_{i}-C_{i}\left(q_{i}\right)\right\} .
$$

For some function $\Psi_{i}(q)$, this program can be equivalently expressed as

$$
\max _{q_{\mathrm{i}} \in \mathrm{R}_{+}}\left\{\Psi_{i}\left(q_{i}, q_{-i}^{*}\right) \partial_{i} u\left(q_{i}, q_{-i}^{*}\right) q_{i}-C_{i}\left(q_{i}\right)\right\} .
$$

with first order conditions given by

$$
\mu_{i}^{*}=-\epsilon_{i}\left(D^{-1}\right)_{i}\left(q^{*}\right)=-\epsilon_{i} \Psi_{i}\left(q^{*}\right)-\epsilon_{i} \partial_{i} u\left(q^{*}\right)
$$

Using an alternative expression ${ }^{13}$ for the elasticity $\sigma_{i}^{*}$,

$$
-\left.\frac{d q_{i}}{d p_{i}} \frac{p_{i}}{q_{i}}\right|_{\partial_{\mathrm{u}} e\left(p_{\mathrm{i}}, p_{-\mathrm{i}}^{*}, u\left(q_{\mathrm{i}}, q_{-\mathrm{i}}^{*}\right)\right)=\Psi_{\mathrm{i}}\left(q_{\mathrm{i}}, q_{-\mathrm{i}}^{*}\right)}=\frac{-\varepsilon_{i}^{*}}{\epsilon_{i} \Psi_{i}\left(q^{*}\right)-\epsilon_{u} \partial_{u} e\left(p^{*}, u\left(q^{*}\right)\right) \epsilon_{i} u\left(q^{*}\right)},
$$

as well as formula (30) for $s_{i}^{*}$, we get

$$
\mu_{i}^{*}=\frac{1-\varepsilon_{i}^{*}}{s_{i}^{*}}+\frac{\varepsilon_{i}^{*}}{\sigma_{i}^{*}}
$$

the arithmetic mean of $1 / s_{i}{ }^{*}$ and $1 / \sigma_{i}^{*}$, with weights respectively equal to $1-\varepsilon_{i}^{*}$ and $\varepsilon_{i}^{*}$. Again this could be directly obtained from the general formula (26) if we had taken

$$
\theta_{i}=\frac{\alpha_{i}^{*}}{\alpha_{i}^{*}+\varepsilon_{i}^{*} s_{i}^{*} / \sigma_{i}^{*}} .
$$

where the ratio $s_{i}^{*} / \sigma_{i}^{*}$ can be interpreted as the ratio between intrasectoral substitutability and intersectoral substitutability for good $i$. In spite of their similarity, comparing the two conditions (29) and (31) is not an easy task, in general, since these are equilibrium conditions involving different values of $\alpha_{i}^{*}$ and $\varepsilon_{i}^{*}$. However, in more specific cases, the comparison can be pushed further.

\footnotetext{
${ }^{13}$ As $q=D(p)$ is equivalent to $p=D^{-1}(q) \equiv \times_{i}\left(\Psi_{i}(q) \partial_{i} u(q)\right)$, we see by (4) that the relation $q_{i}=D\left(p_{i}, p_{-i}^{*}\right)$ between the two strategy variables of firm $i$ can be equivalently defined by $\partial_{u} e\left(p_{i}, p_{-i}^{*}, u\left(q_{i}, q_{-i}^{*}\right)\right)=\Psi_{\iota}\left(q_{i}, q_{-i}^{*}\right)$.
} 
An easy example is the case of symmetric equilibria implying $\alpha_{i}^{*}=\varepsilon_{i}^{*}=1 / n$. Then, clearly, the competition regime for a price equilibrium is tougher (resp. softer) than for a quantity equilibrium whenever $s_{i}^{*} / \sigma_{i}^{*}>1($ resp. $<1)$ at the latter equilibrium. The two regimes coincide if $s_{i}^{*} / \sigma_{i}^{*}=1$. In the homothetic sub-utility case, as a consequence of the equality $\alpha_{i}^{*}=\varepsilon_{i}^{*}$, we get the first order conditions of the price equilibrium for $\theta_{i}=1 / 2$, for all $i$, and of the quantity equilibrium for $\theta_{i} \equiv 1 /\left(1+s_{i}^{*} / \sigma^{*}\right)$, for all $i$. Here, even when the equilibria are not symmetric, price and quantity equilibria coincide if and only if $s_{i}^{*} / \sigma^{*}=1$. Otherwise price competition is tougher (resp. softer) than quantity competition whenever $s_{i}^{*} / \sigma^{*}>1($ resp. $<1)$.

\section{The role of coordination and separability}

In order to get the equivalence between the oligopolistic and the common agency games and the resulting parameterization of potential equilibria, we have up to now opted for a fully coordinated version of the common agency game (the socalled intrinsic common agency), and we have relied heavily on the separability of the utility function and the associated partial equilibrium perspective.

\subsection{The non-intrinsic common agency game}

Following the common agency literature, several kinds of participation constraints can be considered, leading to several types of common agency games. In the common agency game we have studied, the intrinsic one, the common agent can only accept (or reject) as a whole the set of contracts proposed by all principals. Another type of game, which can be called non-intrinsic, allows the agent to contract with any principal individually. Then the participation constraint on firm $i$ simply excludes that the sales contract forces the consumer to accept more of good $i$ than what he would optimally buy on the market place at the same prices. This is nothing else than bounding $q_{i}$ by the Walrasian 
demand

$$
q_{i} \leq X_{i}\left(p_{i}, p_{-i}, B\left(p_{i}, p_{-i}\right)\right) \equiv D_{i}\left(p_{i}, p_{-i}\right) .
$$

Correspondingly, one can define the non-intrinsic common agency game by simply using condition (32) in the payoff given by (10) instead of the former participation constraint. In the definition of a non-intrinsic common agency equilibrium, we keep the restriction (15) that consumers are not rationed as for the intrinsic one. At an equilibrium $\left(p^{*}, q^{*}\right) \in \mathbf{R}_{+}^{2 n}$ of this new game, each firm $i$ equilibrium offer should solve the following program:

$$
\begin{aligned}
& \max _{\left(p_{i}, q_{\mathrm{i}}\right) \in \mathrm{R}_{+}^{2}} p_{i} q_{i}-C_{i}\left(q_{i}\right) \\
& \text { s.t. } \frac{q_{i}}{H_{i}\left(p_{i}, p_{-i}^{*}, u\left(q_{i}, q_{-i}^{*}\right)\right)} \leq 1, \\
& \text { and } \frac{q_{i}}{D_{i}\left(p_{i}, p_{-i}^{*}\right)} \leq 1 .
\end{aligned}
$$

Using again formula (17) for this case, together with equation (20), the degree of monopoly of each firm $i$ at equilibrium can be expressed as

$$
\begin{aligned}
\mu_{i}^{*} & =\frac{\theta_{i}\left(1-\varepsilon_{i}^{*}\right)+\left(1-\theta_{i}\right)}{\theta_{i}\left(1-\varepsilon_{i}^{*}\right) s_{i}^{*}+\left(1-\theta_{i}\right)\left(-\epsilon_{p_{\mathrm{i}}} D_{i}\left(p^{*}\right)\right)} \\
& =\frac{\theta_{i}\left(1-\varepsilon_{i}^{*}\right)+\left(1-\theta_{i}\right)}{\left(1-\varepsilon_{i}^{*}\right) s_{i}^{*}+\left(1-\theta_{i}\right) \varepsilon_{i}^{*} \sigma_{i}^{*}} .
\end{aligned}
$$

For the maximal values of competitive toughness $\left(\theta_{i} \equiv 1\right)$, we get the same conditions as above

$$
\mu_{i}^{*}=\frac{1}{s_{i}^{*}},
$$

corresponding to monopolistic competition. For the minimal values, $\theta_{i} \equiv 0$, we get the conditions

$$
\mu_{i}^{*}=-\frac{1}{\epsilon_{p_{\mathrm{i}}} D_{i}\left(p^{*}\right)},
$$

which correspond to the first order conditions of a price equilibrium.

This suggests that going from the intrinsic to the non-intrinsic common agency game reduces the set of equilibria. The following proposition confirms this claim. 


\section{Proposition 2 The set of non-intrinsic common agency equilibria is included} in the set of intrinsic common agency equilibria.

P roof. Suppose $\left(p^{*}, q^{*}\right) \in \mathbf{R}_{+}^{2 n}$ is an equilibrium of the non-intrinsic common agency game, but not of the intrinsic common agency game. This means that there exists, for some firm $i$, a pair $\left(p_{i}, q_{i}\right) \in \mathrm{R}_{+}^{2}$ such that $p_{i} q_{i}-C_{i}\left(q_{i}\right)>p_{i}^{*} q_{i}^{*}-$ $C_{i}\left(q_{i}^{*}\right), D_{i}\left(p_{i}, p_{-i}^{*}\right)<q_{i} \leq H_{i}\left(p_{i}, p_{-i}^{*}, u\left(q_{i}, q_{-i}^{*}\right)\right)$ and $e\left(p_{i}, p_{-i}^{*}, u\left(q_{i}, q_{-i}^{*}\right)\right) \leq$ $B\left(p_{i}, p_{-i}^{*}\right)$. Thus, $H_{i}\left(p_{i}, p_{-i}^{*}, \bar{D}\left(p_{i}, p_{-i}^{*}\right)\right)=D_{i}\left(p_{i}, p_{-i}^{*}\right)<H_{i}\left(p_{i}, p_{-i}^{*}, u\left(q_{i}, q_{-i}^{*}\right)\right)$, so that $\bar{D}\left(p_{i}, p_{-i}^{*}\right)<u\left(q_{i}, q_{-i}^{*}\right)$, implying $B\left(p_{i}, p_{-i}^{*}\right)=e\left(p_{i}, p_{-i}^{*}, \bar{D}\left(p_{i}, p_{-i}^{*}\right)\right)<$ $e\left(p_{i}, p_{-i}^{*}, u\left(q_{i}, q_{-i}^{*}\right)\right)$, a contradiction.

In fact, the reduction of the set of equilibria in the non-intrinsic case can be drastic. In the homothetic case, whenever the industry goods are more substitutable among themselves than for the outside good, the set of non-intrinsic common agency equilibria shrinks to the single monopolistic equilibrium when the number of firms increases (the price equilibrium converges to the monopolistic competition equilibrium as the budget shares tend to zero). More drastically yet, in the limit case of perfect substitutability the Bertrand outcome is the sole equilibrium of the non-intrinsic common agency game, whatever the number $n$ of firms $(n \geq 2)$. By contrast, in the opposite limit case, with perfect complementarity, the set of equilibria of the intrinsic and non-intrinsic games coincide.

\subsection{The global common agency games}

To obtain our results our approach has exploited the existence of a sub-utility. This can be contrasted to a global approach in which both the incentive compatibility and the participation constraints are defined in terms of the global utility function $U$. To introduce this formulation, we need to define the global expenditure and Hicksian demand functions:

$$
\begin{aligned}
\widetilde{e}(p, \underline{U}) & \equiv \min _{(x, z) \in \mathrm{R}_{+}^{n+1}}\{p x+z: U(u(x), z) \geq \underline{U}\}, \\
\widetilde{H}_{i}(p, \underline{U}) & \equiv \arg \min _{(x, z) \in \mathrm{R}_{+}^{n+1}}\{p x+z: U(u(x), z) \geq \underline{U}\}, \underline{U} \in \mathbf{R} .
\end{aligned}
$$

The Walrasian demand function $D_{i}(p)$ remains unchanged. 
Referring to the intrinsic global common agency game (game (10) reformulated in global terms), we may define an intrinsic global common agency equilibrium $\left(p^{*}, q^{*}\right)$ as a solution to the following programs (for $\left.i=1, \ldots, n\right)$ :

$$
\begin{aligned}
& \max _{\left(p_{\mathrm{i}}, q_{\mathrm{i}}\right) \in \mathrm{R}_{+}^{2}} p_{i} q_{i}-C_{i}\left(q_{i}\right) \\
& \text { s.t. } q_{i} \leq \widetilde{H}_{i}\left(p_{i}, p_{-i}^{*}, U\left(u\left(q_{i}, q_{-i}^{*}\right), w-p_{i} q_{i}-p_{-i}^{*} q_{-i}^{*}\right)\right), \\
& \text { and } \widetilde{e}\left(p_{i}, p_{-i}^{*}, U\left(u\left(q_{i}, q_{-i}^{*}\right), w-p_{i} q_{i}-p_{-i}^{*} q_{-i}^{*}\right)\right) \leq w,
\end{aligned}
$$

satisfying the additional restriction:

$$
q_{i}^{*}=\widetilde{H}_{i}\left(p^{*}, U\left(u\left(q^{*}\right), w-p^{*} q^{*}\right)\right)=D_{i}\left(p^{*}\right), i=1, \ldots, n .
$$

In the non-intrinsic case the participaton constraint is replaced by $q_{i} \leq D_{i}\left(p_{i}, p_{-i}^{*}\right)$.

In the global games, we get a drastically reduced set of equilibria.

Proposition 3 If $\left(p^{*}, q^{*}\right) \in \mathbf{R}_{+}^{2 n}$ is an intrinsic (resp. non-intrinsic) global common agency equilibrium then it is a price equilibrium.

Proof. Clearly, the second constraint of the intrinsic common agency game always holds as an equality:

$$
\widetilde{e}\left(p_{i}, p_{-i}^{*}, U\left(u\left(q_{i}, q_{-i}^{*}\right), w-p_{i} q_{i}-p_{-i}^{*} q_{-i}^{*}\right)\right) \equiv w .
$$

Then the indirect utility function $V(p, w)$ satisfies:

$$
\begin{aligned}
V\left(p_{i}, p_{-i}^{*}, w\right) & =V\left(p_{i}, p_{-i}^{*}, \widetilde{e}\left(p_{i}, p_{-i}^{*}, U\left(u\left(q_{i}, q_{-i}^{*}\right), w-p_{i} q_{i}-p_{-i}^{*} q_{-i}^{*}\right)\right)\right) \\
& =U\left(u\left(q_{i}, q_{-i}^{*}\right), w-p_{i} q_{i}-p_{-i}^{*} q_{-i}^{*}\right),
\end{aligned}
$$

so that

$$
\begin{aligned}
\widetilde{H}_{i}\left(p_{i}, p_{-i}^{*}, U\left(u\left(q_{i}, q_{-i}^{*}\right), w-p_{i} q_{i}-p_{-i}^{*} q_{-i}^{*}\right)\right) & =\widetilde{H}_{i}\left(p_{i}, p_{-i}^{*}, V\left(p_{i}, p_{-i}^{*}, w\right)\right) \\
& =D_{i}\left(p_{i}, p_{-i}^{*}\right),
\end{aligned}
$$

from standard properties. Therefore the two constraints in the two global common agency games (intrinsic and non-intrinsic) reduce to a single one, namely $q_{i} \leq D_{i}\left(p_{i}, p_{-i}^{*}\right)$. The result follows. 


\section{Symmetric equilibria with quadratic sub-utility}

Coming back to the intrinsic common agency game, and in order to visualize the set of common agency equilibria in a simple case, we suppose that all firms have an identical cost function $C$, with constant marginal cost $C^{\prime} \equiv 1$, and that the representative consumer has a quadratic sub-utility. This utility specification is frequently chosen for oligopoly modelling, as it leads to linear Walrasian demands. More specifically, we assume that the utility function $U$ is quasilinear, with symmetric sub-utility $u$ given by

$$
u(x)=\beta \sum_{i=1}^{n} x_{i}-\frac{1}{2} \sum_{i=1}^{n} x_{i}^{2}-\frac{\gamma}{2}\left(\sum_{i=1}^{n} x_{i}\right)^{2},
$$

with $\beta>0$ and $\gamma>-1 / n$, and with $x$ constrained to satisfy for any $i$ :

$$
\partial_{i} u(x)=\beta-x_{i}-\gamma \sum_{j} x_{j} \geq 0 .
$$

The parameter $\beta$ is the consumer's reservation price, and can be seen as an index of market size. The substitutability among industry goods is increasing in $\gamma$, with the two limit cases where the goods become perfect substitutes (when $\gamma$ and $\beta$ tend both to infinity) and where they become perfect complements (when $\gamma$ tends to $-1 / n)$.

\subsection{Symmetric equilibria and uniform competitive tough- ness}

Letting $\mathbf{S}=1+n \gamma \in(0, \infty)$, and solving in $x$ the equation $p=\partial_{u} e(p, \underline{u}) \partial u(x)$ (see (4)), we obtain the Hicksian demand for good $i$

$$
H_{i}(p, \underline{u})=\frac{1}{\mathbf{s}}\left(\beta-\frac{\mathbf{s} p_{i}+(1-\mathbf{s})(1 / n) \sum_{j} p_{j}}{\partial_{u} e(p, \underline{u})}\right),
$$

for any $\underline{u} \in\left(0, n \beta^{2} / 2 \mathrm{~s}\right)$ and any admissible price vector $p$ (i.e. entailing a non-negative vector $x$ ), and implying:

$$
\partial_{u} e(p, \underline{u})=\sqrt{\frac{\sum_{j} p_{j}\left(\mathbf{S} p_{j}+(1-\mathbf{s})(1 / n) \sum_{k} p_{k}\right)}{n \beta^{2}-2 \mathbf{s} \underline{u}}},
$$


since $u(H(p, \underline{u}))=\underline{u}$. The Walrasian demand for good $i$ coincides with the Hicksian demand if and only if $\partial_{u} e(p, \underline{u})=1$, implying:

$$
D_{i}(p)=\beta / \mathrm{s}-p_{i}-(1 / \mathrm{s}-1)(1 / n) \sum_{j} p_{j} .
$$

Consider a symmetric equilibrium $\left(p^{*}, q^{*}\right)=\left(\left(\bar{p}^{*}, \ldots, \bar{p}^{*}\right),\left(\bar{q}^{*}, \ldots, \bar{q}^{*}\right)\right) \in(0, \beta)^{n} \times$ $(0, \beta / \mathbf{s})^{n}$ and uniform competitive toughness $\bar{\theta} \in[0,1]$. Because $\left(p^{*}, q^{*}\right)$ is an equilibrium, $\partial_{u} e\left(p^{*}, u\left(q^{*}\right)\right)=1$. Then, the elasticity of substitution $s_{i}$ of any good $i$ for the industry composite good (as given by (20) and (21)) and the elasticity of demand to the industry $\sigma_{i}$ via good $i$ (as computed from (25) using $B(p)=p D(p))$ simplify respectively to

$$
s_{i}\left(p^{*}, u\left(q^{*}\right)\right)=\frac{\mathrm{s}}{\beta / \bar{p}^{*}-1} \text { and } \sigma_{i}\left(p^{*}\right)=\frac{1}{\beta / \bar{p}^{*}-1},
$$

so that the parameter $\mathbf{S}$ appears as the ratio between intra- and intersectoral substitutabilities. The degree of monopoly becomes:

$$
\mu^{*}=\frac{\bar{\theta}(1-\alpha)+(1-\bar{\theta}) \alpha}{\bar{\theta}(1-\alpha) \mathbf{S}+(1-\bar{\theta}) \alpha}\left(\beta / \bar{p}^{*}-1\right)
$$

where $\alpha=1 / n$ is the market share of each individual firm, which by symmetry appears as a measure of concentration in the industry. Since we have a constant unitary marginal cost, we get $\bar{p}^{*}=1 /\left(1-\mu^{*}\right)$, and the price can be eliminated in the preceding equation. We thus obtain:

$$
\mu^{*}=\frac{\beta-1}{\beta+\frac{\bar{\theta}(1-\alpha) \mathbf{S}+(1-\bar{\theta}) \alpha}{\bar{\theta}(1-\alpha)+(1-\bar{\theta}) \alpha}} \equiv \mu(\bar{\theta}, \mathbf{S}, \alpha, \beta),
$$

the degree of monopoly thus depending upon the competitive toughness $\bar{\theta} \in$ $[0,1]$, the ratio between intra- and intersectoral substitutabilities $\mathbf{S} \in(0, \infty)$, the degree of concentration $\alpha \in(0,1 / 2]$ and the market size $\beta \in(1, \infty)$.

The degree of monopoly $\mu^{*}$ increases from 0 to 1 as the consumer's reservation price $\beta$ increases from 1 (the marginal cost) to infinity, inducing a continuous increase in market size and a continuous decrease in the elasticity of demand 
to the industry. Also, given $\beta$, the degree of monopoly varies between two extremes. One is the monopolistic competition value which may be associated either with zero concentration (and arbitrary positive competitive toughness) or with maximum toughness of competition between at least two firms:

$$
\left.\mu(\bar{\theta}, \mathbf{S}, 0, \beta)\right|_{\bar{\theta}>0}=\frac{\beta-1}{\beta+\mathbf{S}}=\left.\mu(1, \mathbf{S}, \alpha, \beta)\right|_{\alpha<1},
$$

The other extreme is the monopoly (or collusive) value associated either with maximum concentration (and less than maximum competitive toughness) or, alternatively, with minimum toughness of competition between a finite number of firms:

$$
\left.\mu(\bar{\theta}, \mathbf{S}, 1, \beta)\right|_{\bar{\theta}<1}=\frac{\beta-1}{\beta+1}=\left.\mu(0, \mathbf{S}, \alpha, \beta)\right|_{\alpha>0} .
$$

Notice that the monopolistic competition value of $\mu^{*}$ is lower (resp. higher) than the collusive value if $\mathbf{S}>1$ (resp. $\mathbf{S}<1$ ). Finally, as symmetry entails $\epsilon_{p_{\mathrm{i}}} \partial_{u} e\left(p^{*}, u\left(q^{*}\right)\right)=\alpha$, one readily determines the values of $\mu^{*}$ corresponding to price equilibrium

$$
\mu\left(\frac{1}{2}, \mathbf{S}, \alpha, \beta\right)=\frac{\beta-1}{\beta+(1-\alpha) \mathbf{S}+\alpha},
$$

and to quantity equilibrium

$$
\mu\left(\frac{1}{1+\mathbf{S}}, \mathbf{S}, \alpha, \beta\right)=\frac{\beta-1}{\beta+\frac{1}{(1-\alpha) / \mathbf{S}+\alpha}} . .
$$

The range of $\mu^{*}$ we have been considering refers to potential equilibria only. Indeed, as we will now illustrate, equilibria close to the collusive solution do not always exist. For high relative substitutability, firms have an incentive to deviate from symmetric strategy profiles close to the collusive one by decreasing their prices, in order to compete for a higher (responsive) market share. At the other extreme, when relative substitutability is very small, firms have an incentive to deviate from such profiles by increasing their prices, taking advantage of an unresponsive market share. 


\subsection{The duopoly case}

In order to construct an example where a degree of monopoly close to its collusive value is not enforceable, it suffices to consider the case of a duopoly ( $\alpha=1 / 2)$, leading to uniform equilibrium price $\bar{p}^{*}=1 /\left(1-\mu^{*}\right)$ and quantity $\bar{q}^{*}=\left(\beta-\bar{p}^{*}\right) / \mathrm{s}$, with degree of monopoly

$$
\mu^{*}=\frac{\beta-1}{\beta+1+\bar{\theta}(\mathbf{s}-1)} .
$$

We need to describe precisely the admissible strategy set of a particular firm when considering a deviation at a potential equilibrium. By referring to the first order condition of consumer's expenditure minimizing problem $\left(p_{i} / \partial_{i} u\left(q_{i}, \bar{q}^{*}\right)=\right.$ $\bar{p}^{*} / \partial_{j} u\left(q_{i}, \bar{q}^{*}\right)=\partial_{u} e\left(p_{i}, \bar{p}^{*}, u\left(q_{i}, \bar{q}^{*}\right)\right)$ as long as the consumer is not rationed), and integrating the admissibility condition (37), the incentive compatibility constraint can be expressed as

$$
\begin{aligned}
\frac{p_{i}}{\bar{p}^{*}} & \leq \frac{2 \beta / \bar{q}^{*}-(\mathbf{s}-1)-(\mathbf{s}+1) q_{i} / \bar{q}^{*}}{2 \beta / \bar{q}^{*}-(\mathbf{s}+1)-(\mathbf{s}-1) q_{i} / \bar{q}^{*}} \\
\text { for } q_{i} / \bar{q}^{*} & \in\left[0, \frac{2 \beta / \bar{q}^{*}-(\mathbf{s}-1)}{\mathbf{S}+1}\right] \text { if } \mathbf{s} \geq 1 \\
\text { for } q_{i} / \bar{q}^{*} & \in\left[\max \left\{0, \frac{1+\mathbf{S}-2 \beta / \bar{q}^{*}}{1-\mathbf{S}}\right\}, \frac{2 \beta / \bar{q}^{*}+1-\mathbf{s}}{1+\mathbf{S}}\right] \text { if } \mathbf{s}<1 .
\end{aligned}
$$

Because of quasi-linearity of the utility function, the participation constraint for firm $i$ can be expressed in the form of the inequality $\partial_{u} e\left(p_{i}, \bar{p}^{*}, u\left(q_{i}, \bar{q}^{*}\right)\right) \leq 1$, so that the incentive compatibility constraint is relevant only if $\bar{p}^{*} / \partial_{j} u\left(\bar{q}^{*}, q_{i}\right) \leq 1$, leading to $(\mathbf{s}-1) q_{i} / \bar{q}^{*} \leq \mathbf{s}-1$, that is, $q_{i} / \bar{q}^{*} \leq 1$ if $\mathbf{S}>1$ and $q_{i} / \bar{q}^{*} \geq 1$ if $\mathbf{S}<1$.

The participation constraint can also be expressed as $u\left(q_{i}, \bar{q}^{*}\right) \leq u\left(D\left(p_{i}, \bar{p}^{*}\right)\right)$, showing that we must take into account, the case where, for $\mathbf{S}>1$ and a small price $p_{i}, D_{j}\left(p_{i}, \bar{p}^{*}\right)=0$ as well as the case where, for $\mathbf{S}<1$ and a small quantity $q_{i}, \partial_{j} u\left(q_{i}, \bar{q}^{*}\right)=0$. This gives, using the definitions of $u$ and $D_{i}$ in (36) and (40) respectively:

$$
u\left(q_{i}, \bar{q}^{*}\right) \leq u\left(2 \frac{\beta-p_{i}}{\mathbf{S}+1}, 0\right) \text { for } \frac{p_{i}}{\bar{p}^{*}} \leq \frac{\mathbf{S}+1-2 \beta / \bar{p}^{*}}{\mathbf{S}-1} \text { and } \mathbf{S}>1,
$$




$$
\begin{aligned}
u\left(q_{i}, \frac{2 \beta+(1-\mathrm{s}) q_{i}}{1+\mathrm{s}}\right) \leq & u\left(D_{i}\left(p_{i}, \bar{p}^{*}\right), D_{j}\left(p_{i}, \bar{p}^{*}\right)\right) \\
& \text { for } \frac{q_{i}}{\bar{q}^{*}} \leq \frac{1+\mathrm{s}-2 \beta / \bar{q}^{*}}{1-\mathrm{s}} \text { and } \mathrm{s}<1 \\
u\left(q_{i}, \bar{q}^{*}\right) \leq & u\left(D_{i}\left(p_{i}, \bar{p}^{*}\right), D_{j}\left(p_{i}, \bar{p}^{*}\right)\right) \text { otherwise. }
\end{aligned}
$$

We can now construct two cases of unsustainable collusive (or close to collusive) degree of monopoly, as each firm has an incentive to deviate to a low (resp. high) price because of excessive substitutability (resp. complementarity) inside the industry. We take $\beta=4$, leading to a collusive value of the degree of monopoly equal to 0.6. The examples represented in Figures 1 and 2 are computed by taking $\mathbf{S}=50$ with $\mu=0.59$, and $\mathbf{S}=0.02$ with $\mu=0.63$, respectively. The relative quantity $Q=q_{i} / \bar{q}^{*}$ is measured along the horizontal axis, the relative price $P=p_{i} / \bar{p}^{*}$ along the vertical axis. The admissible strategy set is upper-bounded by the solid broken curve, where the segments corresponding to $Q>1$ and $P<1$ (resp. $Q<1$ and $P>1$ ) represent the two pieces of the participation constraint for $\mathbf{S}>1$ (resp. $\mathbf{S}<1$ ). The dotted curve is the isoprofit curve through the potential equilibrium point $(1,1)$, which is clearly not an equilibrium in these examples.

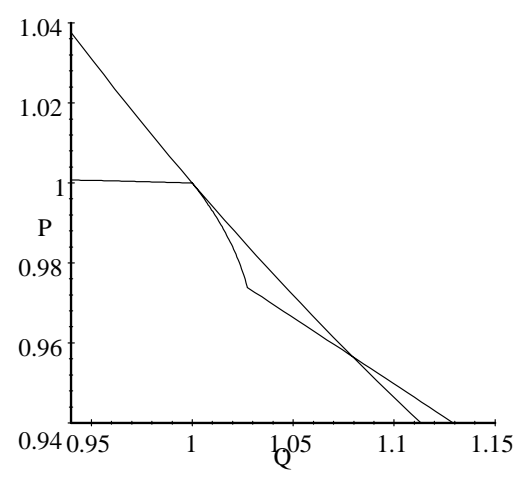

Figure 1: $\mathbf{S}=50, \mu=0.59$

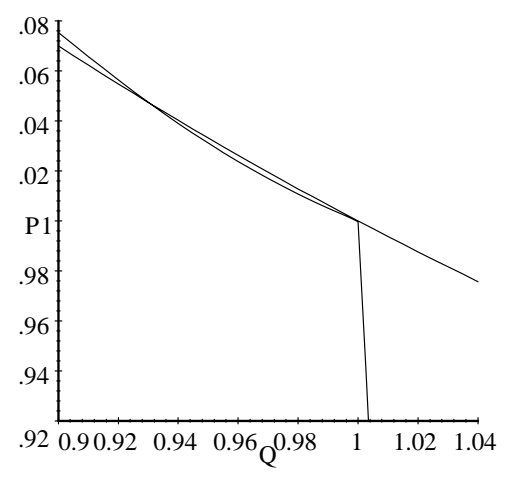

Figure 2: $\mathbf{S}=0.02, \mu=0.63$

Finally, we represent in Figure 3, for each degree of complementarity $\kappa=$ $1 /(1+\mathrm{s}) \in[0,1]$ measured along the horizontal axis (and for $\beta=4$ ), the set of degrees of monopoly $\mu^{*}$ that are enforceable at a symmetric duopolistic equilibrium. This set is bounded by two solid curves. The first one results 
from minimum admissible competitive toughness, thus coinciding with the collusive level of the degree of monopoly $\mu(0, \mathrm{~s}, .5,4)=.6$ for intermediate degrees of complementarity. It ends up, at the two extremes, in the Cournotian values $\mu(0, \infty, .5,4)=1 / 2$ and $\mu(.5,0, .5,4)=2 / 3$ corresponding to the cases of homogeneous oligopoly $(\kappa=0)$ and complementary monopolies $(\kappa=1)$, respectively. The second boundary results from maximum competitive toughness, and corresponds to the values of the degree of monopoly $\mu(1, \mathrm{~S}, .5,4)$ associated with monopolistic competition (perfect competition when $\kappa=0$ ). The two dotted, concave and convex, curves represent the degrees of monopoly in price and quantity equilibrium, respectively. They both link the two opposite extremes of the boundaries of the equilibrium set.

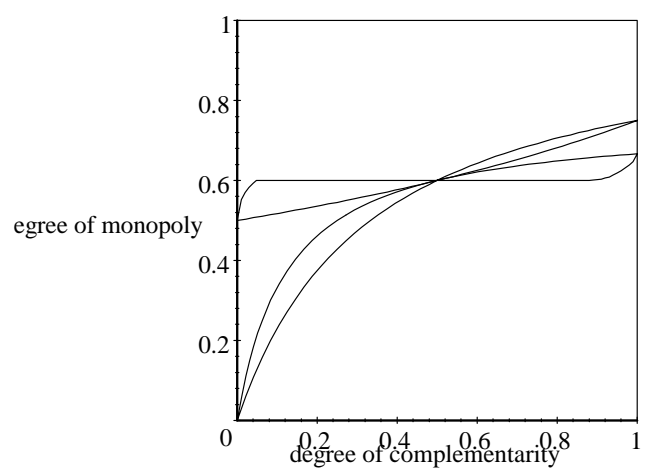

Figure 3

As well illustrated in this example, the logic of competitive toughness changes the perspective in which we consider oligopolistic equilibria quite drastically: for instance, the two Cournot equilibria now appear unified, as resulting from the selection of the least possible competitive equilibrium, instead of looking like the two dual outcomes of price competition and quantity competition.

\section{Conclusion}

In this analysis, we have tried to shed more light on the oligopoly problem through its reformulation in the multi-principal common agency framework. 
Several types of common agency games have been presented, varying according to the kind of participation constraint, (intrinsic or non-intrinsic) and to the kind of approach (partial or global). It seems that the best account of the oligopoly problem is given by the partial equilibrium and intrinsic formulation of the common agency game. This is the formulation that allows to integrate the largest variety of contractual arrangements and industry norms of conduct, leading naturally to some degree of indeterminacy in the characterization (from first order conditions) of the set of potential oligopolistic equilibria, and its parameterization in terms of competitive toughness. However, the set of contracts that are fully (and not only potentially) enforceable as oligopolistic equilibria, varies with the fundamentals of the economy, including the structure of the industry and the degree of good heterogeneity. This correctly reflects the multidimensionality of competition intensity and shows that the crucial issue in the oligopoly problem is the determination of this set in different environments.

\section{R eferences}

d'Aspremont C., R. Dos Santos Ferreira and L.-A. Gérard-Varet (1991a) "Pricing Schemes and Cournotian Equilibria," American Economic Review, 1991, 81 (3), pp.666-72.

d'Aspremont C., R. Dos Santos Ferreira and L.-A. Gérard-Varet (1991b) "Concurrence en prix et équilibres cournotiens," Revue économique, 42 (6), pp.967-96.

d'Aspremont C., R. Dos Santos Ferreira and L.-A. Gérard-Varet (2003) "Competition for market share or for market size: oligopolistic equilibria with varying competitive toughness," CORE DP 2003/10.

Bernheim B. D. and M. D. Whinston (1986) "Common Agency," Econometrica, 54(4), 923-942.

Cournot A. (1838) Recherches sur les principes mathématiques de la théorie des richesses, Paris: Hachette [English transl. by N. T. Bacon, London: Hafner Publishing Company Ltd., 1960 (first edition: 1897)]. 
Davidson C. and R. Deneckere (1986) "Long-run competition in capacity, short-run competition in price, and the Cournot model," Rand J ournal of Economics, 17, pp.404-415.

Doyle C. (1988) "Different selling strategies in Bertrand oligopoly," Economics Letters, 28, pp. 387-90.

Grether D. M. and C. R. Plott (1984) "The effects of market practices in oligopolistic markets: an experimental examination of the Ethyl case," Economic Enquiry, 22, pp. 479-507.

Holt C. A. and D. T. Scheffman (1987) "Facilitating practices: the effects of advance notice and best-price poicies," Rand J ournal of Economics, 18(2), pp. 187-97.

Kalai E. and M. A. Satterthwaite (1986) "The kinked demand curve, facilitating practices and oligopolistic coordination, MEDS Discussion Paper 677, Northwestern University.

Kreps D. and Scheinkman, J.A. (1983) "Quantity Pre-Commitment and Bertrand Competition Yield Cournot Outcomes." B ell J ournal of E conomics, 14, pp. 326-337.

Laussel D. and M. Le Breton (2001) "Conflict and Cooperation: The Structure of Equilibrium Payoffs in Common Agency," J ournal of Economic Theory, 100, 93-128.

Martimort D. (1992) "Multi-principaux avec anti-sélection," Annales d'E conomie et de Statistique," 28, 1-38.

Martimort D. (1996) "Exclusive Dealing, Common Agency, and Multiprincipals Incentive Theory," RAND J ournal of E conomics, 27, 1-31.

Martimort D. and L. A. Stole (2002) "The Revelation and Delegation Principles in Common Agency Games," Econometrica, 70(4), 1659-1673.

Martimort D. and L. A. Stole (2003a) "Contractual Externalities and Common Agency Equilibria," mimeo.

Martimort D. and L. A. Stole (2003b) "Market Participation under Delegated and Intrinsic Common Agency Games," mimeo.

Mezetti C. (1997) "Common Agency with Horizontally Differentiated Prin- 
cipals," RAND J ournal of Economics, 28, 323-345.

Peters, M. (2001) "Common Agency and the Revelation Principle," E conometrica, 69(5), 1349-1372.

Salop S.C. (1986) "Practices that (credibly) facilitate oligopoly coordination" in New Developments in the Analysis of Market Structure (J. E. Stiglitz and G. F. Mathewson, eds.), International Economic Association: Macmillan Press.

Sonnenschein H. (1968) "The Dual of Duopoly is Complementary Monopoly: or, Two of Cournot's Theories are One," J ournal of Political Economy, 76, 316318.

Stole L. (1991) "Mechanism Design under Common Agency," chapter 1, PhD., MIT. 
Département des Sciences Économiques de l'Université catholique de Louvain

Institut de Recherches Économiques et Sociales

Place Montesquieu, 3

1348 Louvain-la-Neuve, Belgique 